\title{
UMEDECIMENTO E SUBSTRATOS PARA GERMINAÇÃO DE SEMENTES DE REPOLHO ${ }^{1}$
}

\author{
Gilvaneide Alves de Azeredo ${ }^{2}$, Breno Marques da Silva e Silva ${ }^{3}$, Rubens Sader ${ }^{3}$, Valderez Pontes Matos ${ }^{4}$
}

\begin{abstract}
SUBSTRATES AND MOISTURE LEVELS

IN THE GERMINATION OF CABBAGE SEEDS

The availability of water for seeds is closely related to their germination, since hydration is a limiting factor for their metabolic processes. Therefore, in tests carried out in laboratory, substrate must be sufficiently moistened, in order to assure both the embryo growth and seedling formation. This research was carried out to evaluate the influence of different quantities of water, in different substrates, for cabbage (Brassica oleracea var. capitata) seeds germination. The seeds, processed with Thiran $0.1 \%$, were obtained in shops located in Jaboticabal, São Paulo State, Brazil. Germination tests were made in germitest rolled paper towel substrates, between and on draft paper, moistened with quantities of water equivalent to $1.0 ; 1.5 ; 2.0 ; 2.5 ; 3.0$; 3.5 ; and 4.0 times the dry substrate weight. For each treatment, four repetitions of 50 seeds were used. The seeds were kept in a germinator, at an alternate temperature of $20-30^{\circ} \mathrm{C}$, without further addition of water to the substrate. The evaluations were made on the fifth and tenth days after the experiment preparation. The results obtained revealed that the quantities of water ranging from 1.5 to 2.5 times the paper weight were favorable for seeds germination, mainly in the substrate on and between the paper, while water levels above 3.0 times the substrate weight were harmful for cabbage seeds germination in the rolled paper towel substrates and between the paper.
\end{abstract}

KEY-WORDS: Brassica oleracea var. capitata; quantity of water; seed analysis; germination test.

\section{INTRODUÇÃO}

O repolho (Brassica oleraceae var. capitata L.), da família Brassicaceae, é uma planta herbácea, folhosa, com grande versatilidade, não somente pelo seu valor nutritivo, sobretudo cálcio, proteína e vitamina $\mathrm{C}$, constituindo-se em alimento de ex-

\section{RESUMO}

A disponibilidade de água para sementes está diretamente relacionada com a sua germinação, uma vez que a hidratação é fator limitante dos processos metabólicos que ocorrem na semente. Assim, em testes realizados em laboratório, o substrato deve estar suficientemente úmido, visando a garantir o crescimento do embrião e a formação da plântula. Este trabalho foi conduzido com o objetivo de avaliar a influência de diferentes teores de água, em diferentes substratos, na germinação de sementes de repolho. As sementes, tratadas com Thiran $0,1 \%$, foram obtidas em casas comerciais localizadas em Jaboticabal (SP). Foram conduzidos testes de germinação nos substratos rolo de papel "germitest", entre e sobre papel "mata borrão", umedecidos com teores de água equivalentes a 1,0 ; 1,$5 ; 2,0 ; 2,5 ; 3,0 ; 3,5$; e 4,0 vezes a massa do substrato seco. Para cada tratamento, foram empregadas quatro repetições de 50 sementes, que foram mantidas em germinador, à temperatura alternada de $20-30^{\circ} \mathrm{C}$, sem adição posterior de água ao substrato. As avaliações foram efetuadas aos cinco e dez dias após a instalação do teste. Os resultados obtidos indicaram que os teores de água, na faixa de 1,5 a 2,5 vezes a massa do papel, foram favoráveis à germinação das sementes, principalmente no substrato sobre e entre papel, enquanto os teores de água acima de 3,0 vezes a massa do substrato foram prejudiciais à germinação das sementes de repolho, nos substratos rolo de papel e entre papel.

PALAVRAS-CHAVE: Brassica oleracea var. capitata; quantidade de água; análise de sementes, teste de germinação.

celente qualidade para grande parte da população (Filgueira 2000, Ledo et al. 2000), mas, também, pelo seu caráter social, por ser uma cultura em que se utiliza muita mão-de-obra, sendo cultivada quase essencialmente por pequenos agricultores (Filgueira 2000).

Dentre os fatores que afetam a germinação de sementes, a umidade é um dos mais importantes,

1. Trabalho recebido em jun./2008 e aceito para publicação em fev./2010 (nº registro: PAT 4010/ DOI: 10.5216/pat.v40i1.4010).

2. Universidade Federal do Tocantins, Escola de Medicina Veterinária e Zootecnia, Araguaína, TO, Brasil. E-mail: azeredogil@yahoo.com.br.

3. Universidade Estadual Paulista (Unesp), Faculdade de Ciências Agrárias e Veterinárias, Departamento de Produção Vegetal, Jaboticabal, SP, Brasil.E-mails: silvabms@hotmail.com, rsader@fcav.unesp.br.

4. Universidade Federal Rural de Pernambuco, Departamento de Agronomia, Recife, PE, Brasil. E-mail: vpmatos@ig.com.br. 
pois é com a absorção de água por embebição que se inicia o processo germinativo (Borges \& Rena 1993). Durante este processo, a absorção de água promove o amolecimento do tegumento e aumento do volume do embrião e dos tecidos de reserva, favorecendo a ruptura do tegumento, a difusão gasosa e a emergência da raiz primária. Proporciona, ainda, a diluição do protoplasma, permitindo a difusão de hormônios e, consequentemente, ativação de sistemas enzimáticos. Com isso, desenvolve-se a digestão, translocação e a assimilação das reservas, resultando no crescimento do embrião (Marcos Filho 2005).

Nos testes de germinação, a quantidade inicial de água a ser adicionada depende da natureza do substrato e, principalmente, das exigências de cada espécie, devendo ser, previamente, determinada, para que sempre seja usada a mesma quantidade nos testes de rotina (Figliolia et al. 1993). Assim, o conhecimento das condições adequadas para a germinação de sementes é de fundamental importância, principalmente pelas respostas diferenciadas que podem apresentar, devido a diversos fatores, como dormência, condições ambientais (água, luz, temperatura e oxigênio) e ocorrência de agentes patogênicos associados ao substrato (Popinigis 1985, Brasil 1992, Carvalho \& Nakagawa 2000).

Estudos sobre a exigência de água em sementes de espécies agrícolas foram desenvolvidos por Phaneendranath (1980), Eira \& Barros (1987), Tanaka et al. (1991) e Novembre \& Marcos Filho (1999), os quais têm mostrado que a umidade pode ser regulada/controlada, através de cálculo na relação teor de água e massa do substrato do papel, sem umedecê-lo, posteriormente.

Em laboratório, durante a realização do teste de germinação, o substrato deve permanecer suficientemente úmido, a fim de suprir as sementes com a quantidade de água necessária para sua germinação e desenvolvimento inicial das plântulas. A adição de água, no decorrer do teste, deve ser evitada, para não alterar as condições do teste (Figliolia et al. 1993). O excesso de umidade provoca um decréscimo na germinação, visto que dificulta a respiração e reduz todo o processo metabólico resultante, levando à redução na viabilidade (Borges \& Rena 1993), além de contribuir para a proliferação de patógenos (Pacheco et al. 2006).

Estudos sobre a influência da quantidade de água no substrato, sobre a germinação de sementes de repolho, não estão disponíveis na literatura. Nas Regras para Análise de Sementes (Brasil 1992), estão contidas informações baseadas na relação teor de água por massa de substrato seco. Portanto, pesquisas desenvolvidas com o intuito de avaliar a influência de diferentes teores de água no substrato são importantes para minimizar as variações nos resultados dos testes de germinação em laboratório. Nesse sentido, este trabalho objetivou avaliar a germinação de sementes de repolho, em função do aumento dos teores de água nos substratos rolo de papel "germitest", entre e sobre papel "mata borrão".

\section{MATERIAL E MÉTODOS}

O trabalho foi desenvolvido em maio de 2006, no Laboratório de Análise de Sementes do Departamento de Produção Vegetal da Faculdade de Ciências Agrárias e Veterinárias da Universidade Estadual Paulista (Unesp), em Jaboticabal, utilizando-se sementes comerciais de repolho tratadas com Thiran $0,1 \%$ e apresentando teor de água inicial de $6,59 \%$, determinado pelo método de estufa a $105 \pm 3{ }^{\circ} \mathrm{C}$, por 17 horas (Brasil 1992).

Os tratamentos estudados constaram da combinação de três substratos de germinação: papel germitest organizado em "rolos", com duas folhas na base e uma sobre as sementes, entre e sobre papel mata-borrão, e sete teores crescentes de água deionizada, para umedecimento do substrato, equivalentes a 1,$0 ; 1,5 ; 2,0 ; 2,5 ; 3,0 ; 3,5 ;$ e 4,0 vezes a massa do substrato (papel) seco. Imediatamente após a aplicação de cada tratamento, procedeu-se à semeadura. No caso do papel mata-borrão, a semeadura foi efetuada utilizando-se caixas plásticas transparentes e com tampa (11 x 11 x 3,5 cm), do tipo "gerbox", em germinador, à temperatura alternada de $20-30^{\circ} \mathrm{C}$ e umidade relativa entre $90 \%$ e $95 \%$ (Brasil 1992), sem adição posterior de água ao substrato.

Adotou-se o delineamento experimental inteiramente casualizado, seguindo o esquema fatorial $3 \times 7$ (substratos $\mathrm{x}$ teores de água), com quatro repetições de 50 sementes.

As contagens foram efetuadas no quinto e no décimo dia após a semeadura, determinando-se a percentagem de plântulas normais, primeira contagem e índice de velocidade de germinação, de acordo com Maguire (1962).

Os dados foram submetidos a análise de variância e as médias de substratos comparadas pelo teste Tukey, a 5\% de probabilidade. Já para as médias dos teores de água, procedeu-se à análise de regressão polinomial. 


\section{RESULTADOS E DISCUSSÃO}

Verificou-se interação $(\mathrm{p}<0,05)$ entre os fatores estudados, para todas as váriáveis analisadas. Com relação à percentagem de germinação (Tabela 1), o substrato sobre papel proporcionou maiores percentagens de germinação, em relação ao substrato rolo de papel, nas quantidades de água de 2,5; 3,0; 3,5 ; e 4,0 vezes a massa do papel seco. Neste substrato, foram verificados os maiores percentuais de germinação ( $92 \%$ e $89 \%$ ), nas quantidades de água de 2,0 e 2,5 vezes a massa seca do papel, apesar de não terem diferido do substrato rolo de papel e entre papel, respectivamente. Gentil \& Torres (2001) também observaram elevada taxa de germinação em sementes de maxixe, nestas mesmas quantidades de água. Quando se utilizou o substrato entre papel, na quantidade de água equivalente a 2,5 vezes a massa do substrato, obteve-se elevada germinação (90\%), apesar de este tratamento só ter diferido do substrato rolo de papel. Este último não favoreceu a germinação das sementes, nas quantidades de água superiores a 2,0 vezes a massa do substrato.

Os resultados da primeira contagem e velocidade de germinação (Tabelas 2 e 3 , respectivamente) confirmaram a mesma tendência observada na variável percentagem de germinação (Tabela 1), ou seja, de que o substrato sobre papel apresentou maior eficiência sobre a germinação de sementes de repolho, nas umidades testadas.

Estudos sobre a influência da quantidade de água no substrato, durante o processo germinativo, são importantes para as espécies em geral, tendo em vista que informações relacionadas à velocidade de

Tabela 1. Percentagem de germinação de sementes de repolho (Brassica oleracea var. capitata), obtidas em diferentes substratos e teores de umidade (Jaboticabal, SP, 2006).

\begin{tabular}{cccc}
\hline Teor de & \multicolumn{3}{c}{ Substratos } \\
\cline { 2 - 4 } umidade $^{1}$ & Rolo de papel & Entre papel & Sobre papel \\
\hline 1,0 & $89 \mathrm{a}^{2}$ & $76 \mathrm{~b}$ & $86 \mathrm{a}$ \\
1,5 & $86 \mathrm{a}$ & $84 \mathrm{a}$ & $87 \mathrm{a}$ \\
2,0 & $87 \mathrm{a}$ & $84 \mathrm{~b}$ & $92 \mathrm{a}$ \\
2,5 & $70 \mathrm{~b}$ & $90 \mathrm{a}$ & $89 \mathrm{a}$ \\
3,0 & $67 \mathrm{~b}$ & $79 \mathrm{a}$ & $85 \mathrm{a}$ \\
3,5 & $63 \mathrm{~b}$ & $73 \mathrm{a}$ & $81 \mathrm{a}$ \\
4,0 & $56 \mathrm{~b}$ & $65 \mathrm{~b}$ & $76 \mathrm{a}$ \\
\hline
\end{tabular}

${ }^{1}$ Fator de multiplicação para determinação da quantidade de água para umedecer o substrato.

${ }^{2}$ Médias seguidas pela mesma letra, na linha, não diferem entre si, pelo teste Tukey, a $5 \%$ de probabilidade.
Tabela 2. Primeira contagem da germinação de sementes de repolho (Brassica oleracea var. capitata), obtidas em diferentes substratos e teores de umidade (Jaboticabal, SP, 2006).

\begin{tabular}{cccc}
\hline Teor de & \multicolumn{3}{c}{ Substratos } \\
\cline { 2 - 4 } umidade $^{1}$ & Rolo de papel & Entre papel & Sobre papel \\
\hline 1,0 & $86 \mathrm{a}$ & $76 \mathrm{~b}$ & $85 \mathrm{a}$ \\
1,5 & $81 \mathrm{a}$ & $67 \mathrm{~b}$ & $87 \mathrm{a}$ \\
2,0 & $76 \mathrm{~b}$ & $82 \mathrm{~b}$ & $91 \mathrm{a}$ \\
2,5 & $57 \mathrm{~b}$ & $88 \mathrm{a}$ & $87 \mathrm{a}$ \\
3,0 & $57 \mathrm{c}$ & $71 \mathrm{~b}$ & $85 \mathrm{a}$ \\
3,5 & $53 \mathrm{c}$ & $66 \mathrm{~b}$ & $79 \mathrm{a}$ \\
4,0 & $39 \mathrm{~b}$ & $45 \mathrm{~b}$ & $75 \mathrm{a}$ \\
\hline
\end{tabular}

${ }^{1}$ Fator de multiplicação para determinação da quantidade de água para umedecer o substrato.

${ }^{2}$ Médias seguidas pela mesma letra, na linha, não diferem entre si, pelo teste Tukey, a $5 \%$ de probabilidade.

Tabela 3. Índice de velocidade de germinação de sementes de repolho (Brassica oleracea var. capitata), obtidas em diferentes substratos e teores de umidade (Jaboticabal, SP, 2006).

\begin{tabular}{cccc}
\hline Teor de & \multicolumn{3}{c}{ Substratos } \\
\cline { 2 - 4 } umidade $^{1}$ & Rolo de papel & Entre papel & Sobre papel \\
\hline 1,0 & $18 \mathrm{a}$ & $15 \mathrm{~b}$ & $17 \mathrm{a}$ \\
1,5 & $17 \mathrm{ab}$ & $15 \mathrm{~b}$ & $18 \mathrm{a}$ \\
2,0 & $16 \mathrm{~b}$ & $17 \mathrm{~b}$ & $18 \mathrm{a}$ \\
2,5 & $13 \mathrm{~b}$ & $18 \mathrm{a}$ & $18 \mathrm{a}$ \\
3,0 & $12 \mathrm{c}$ & $15 \mathrm{~b}$ & $17 \mathrm{a}$ \\
3,5 & $12 \mathrm{c}$ & $14 \mathrm{~b}$ & $16 \mathrm{a}$ \\
4,0 & $10 \mathrm{~b}$ & $11 \mathrm{~b}$ & $15 \mathrm{a}$ \\
\hline
\end{tabular}

${ }^{1}$ Fator de multiplicação para determinação da quantidade de água para umedecer o substrato.

${ }^{2}$ Médias seguidas pela mesma letra, na linha, não diferem entre si, pelo teste Tukey, a $5 \%$ de probabilidade.

hidratação mostram que este fator está ligado à disponibilidade hídrica, potencial mátrico do substrato, temperatura e características intrínsecas da semente (Popinigis 1985, Vertucci \& Leopold 1983 apud Varela et al. 2005).

Para sementes de angelim-pedra (Dinizia excelsa Ducke), as umidades na faixa de 1,5 até 3,0 vezes a massa do substrato foram favoráveis à germinação das sementes, tolerando uma faixa de amplitude de teor de água superior à das sementes de outras espécies agrícolas (Varela et al. 2005), a exemplo das obtidas neste trabalho.

O umedecimento dos substratos, com teores de água superiores a 2,5 vezes a massa do substrato, desfavoreceu o índice velocidade de germinação e a germinação avaliada na primeira contagem, nos 
substratos entre papel, seguido do rolo, enquanto, no substrato sobre papel, este efeito foi mais perceptível na umidade correspondente a 4,0 vezes a massa do papel (Tabelas 2 e 3). Nesses tratamentos, possivelmente, o excesso de água tenha provocado uma deficiência no suprimento de $\mathrm{O}_{2}$, fator essencial no processo de germinação. Com isso, ocorreram dificuldades de aeração e consequente carência de oxigênio e danos provocados pela embebição muito rápida, pois a água, em excesso, limita a entrada de oxigênio, diminuindo a respiração, provocando o atraso ou a paralisação do processo de germinação e, ainda, a ocorrência de plântulas anormais e até o aparecimento de sementes mortas (Peske 1983, Marcos Filho et al. 1987, Borges \& Rena 1993, Carvalho \& Nakagawa 2000).

Os resultados obtidos neste trabalho são similares aos encontrados por Menezes et al. (1993), que verificaram, também, efeitos negativos nas umidades superiores a 3,0 vezes a massa do substrato, na germinação de sementes de pepino, melão e melancia, bem como aos de Gentil \& Torres (2001), com sementes de maxixe. Bisognim et al. (1991) também observaram menor velocidade de germinação em sementes de Lagenaria siceraria, quando utilizaram a proporção de água equivalente a 3,0 vezes a massa do substrato.

Deve ser ressaltado que as Regras para Análise de Sementes não prescrevem o rolo de papel para o teste de germinação de sementes de repolho. No entanto, o mesmo foi testado neste trabalho, para comparação com os demais substratos. Convém destacar, ainda, que os substratos umedecidos com menores quantidades de água $(1,0$ e $1,5 \mathrm{vez})$ não produziram efeitos negativos na germinação das sementes, uma vez que a percentagem de germinação obtida ficou praticamente acima de $80 \%$, com exceção do substrato entre papel, com teor de água de 1,0 vez a massa do substrato, que apresentou $76 \%$ de germinação (Tabela 1).

Os resultados relativos à percentagem de germinação, primeira contagem e índice de velocidade de germinação, em função dos teores de água para os substratos, estão ilustrados nas Figuras 1, 2 e 3, respectivamente. Verificou-se que, para os substratos sobre e entre papel, todas as variáveis estudadas ajustaram-se segundo uma equação quadrática, em função do aumento da umidade no substrato. Já para o substrato rolo de papel, houve decréscimos lineares significativos das variáveis estudadas, em função do aumento da umidade no substrato.
Em relação à germinação (Figura 1) no substrato sobre papel, o acréscimo na quantidade de água no substrato conduziu a um leve aumento no número de plântulas normais, até o nível de umedecimento de 1,98 vezes a massa do papel (ponto de máxima estimado), a partir do qual ocorreu uma leve queda na germinação das sementes. No substrato entre papel, o comportamento foi similar. No entanto, foi verificado aumento no número de plântulas normais, até o nível de umedecimento de

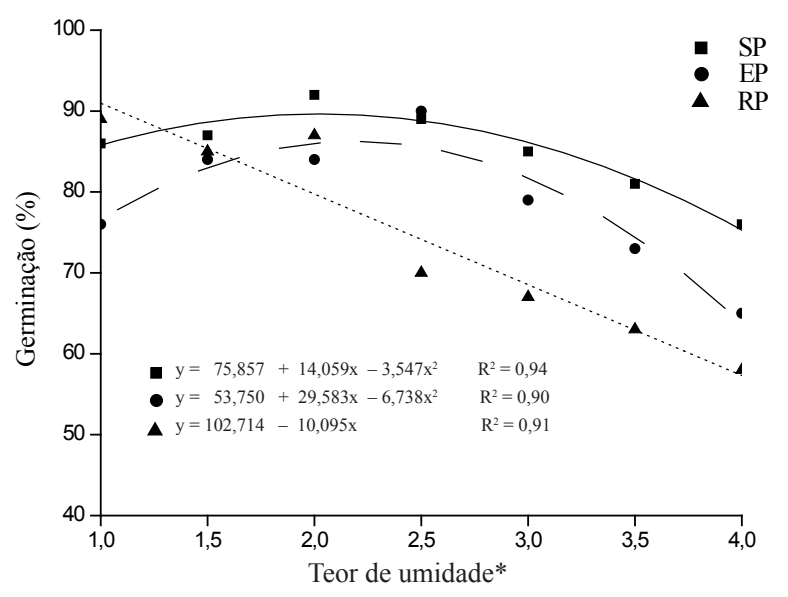

Figura 1. Percentagem de germinação de sementes de Brassica oleracea var. capitata, em função de teores de água e substratos (sobre papel - SP, entre papel - EP e rolo de papel - RP) (Jaboticabal, SP, 2006). *Fator de multiplicação para determinação da quantidade de água para umedecer o substrato.

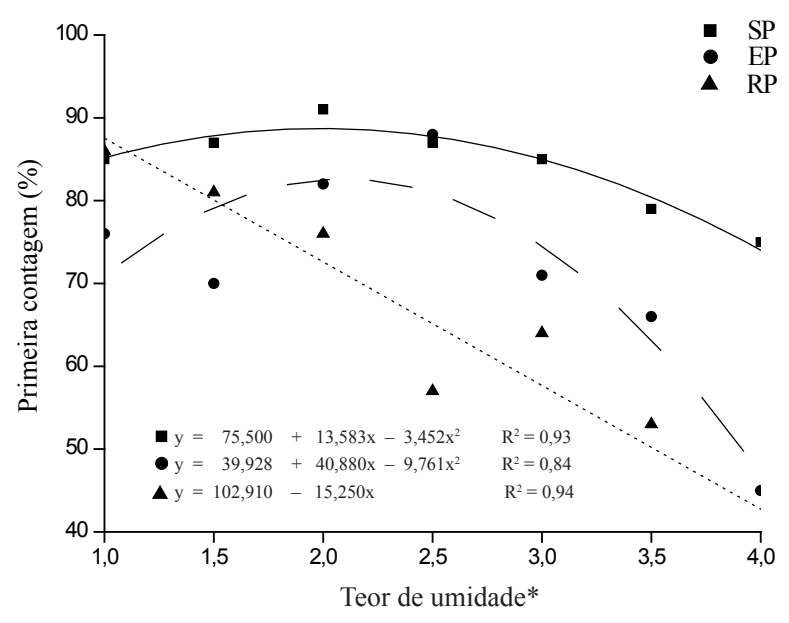

Figura 2. Primeira contagem de germinação de sementes de Brassica oleracea var. capitata, em função de teores de água e substratos (sobre papel - SP, entre papel - EP e rolo de papel - RP) (Jaboticabal, SP, 2006). *Fator de multiplicação para determinação da quantidade de água para umedecer o substrato. 


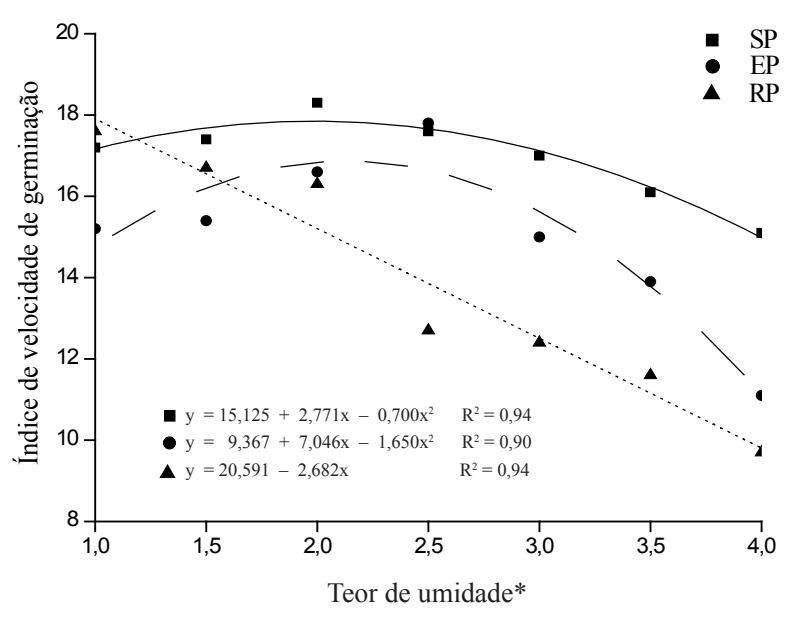

Figura 3. Índice de velocidade de germinação de sementes de Brassica oleracea var. capitata, em função de teores de água e substratos (sobre papel - SP, entre papel - EP e rolo de papel - RP) (Jaboticabal, SP, 2006). *Fator de multiplicação para determinação da quantidade de água para umedecer o substrato.

2,20 (ponto de máxima estimado), ocorrendo, a partir daí, redução um pouco maior, em relação à anterior, no percentual de plântulas normais, nos níveis mais elevados de água. Enquanto houve, neste trabalho com sementes de repolho, influência da umidade do substrato na germinação, em sementes de amendoim não observou-se influência de quantidades de água no substrato de 1,5 até 3,0 vezes a massa do papel, sobre a taxa de germinação das sementes (Tanaka et al. 1991). Quanto ao substrato rolo de papel, foi observado efeito linear decrescente para as variáveis analisadas, à medida que se aumentou o teor de água nos substratos, demonstrando ser este substrato pouco adequado à condução de testes de germinação de sementes de repolho, nos teores de água superiores a 1,5 vezes a massa do substrato.

Para a primeira contagem de germinação (Figura 2) e IVG (Figura 3), o comportamento das curvas de regressão, para os três substratos utilizados, foi semelhante às curvas da germinação (Figura 1). Porém, a diminuição no número de plântulas normais da primeira contagem (Figura 2) foi mais drástica no substrato entre papel, à medida que se aumentou a umidade no substrato. Quanto ao IVG (Figura 3), as curvas de regressão apresentaram a mesma tendência observada na Figura 2. Os pontos de máxima estimados para os substratos sobre papel e entre papel foram da ordem de 1,97 e 2,09 vezes a massa do substrato, respectivamente.

\section{CONCLUSÕES}

1. Os teores de água, na faixa de 2,0 a 2,5 vezes a massa do papel, foram favoráveis à germinação das sementes de repolho, nos substratos sobre e entre papel mata-borrão.

2. Os teores de água superiores a 3,0 vezes a massa do substrato foram prejudiciais à germinação e ao vigor (IVG e primeira contagem) das sementes de repolho, nos substratos papel toalha e entre papel mata-borrão.

\section{REFERÊNCIAS}

BISOGNIM, D. A.; IRIGON, D. L.; MARTINAZZO, A. A. Teste de germinação em porongo - Lagenaria siceraria (Mol.) Standi. Ciência Rural, Santa Maria, v. 21, n. 2, p. 159-167, 1991.

BORGES, E. E. I.; RENA, A. B. Germinação de sementes. In: AGUIAR, J. B.; PIÑA-RODRIGUES, F. C. M.; FIGLIOLIA, M. B. (Eds.). Sementes florestais tropicais. Brasília, DF: Abrates, 1993. p. 83-136.

BRASIL. Ministério da Agricultura e Reforma Agrária. Regras para análise de sementes. Brasília, DF: SNDA/ DNDV/CLAV, 1992.

CARVALHO, N. M.; NAKAGAWA, J. Sementes: ciência, tecnologia e produção. Jaboticabal: Funep, 2000.

EIRA, M. T. S.; BARROS, A. S. R. Influência da quantidade de água no substrato sobre a germinação de sementes de pepino (Cucumis sativus L.). In: CONGRESSO BRASILEIRO DE SEMENTES, 5., 1987, Gramado. Resumos... Gramado: UFPR, 1987. p. 60.

FIGLIOLIA, M. B.; OLIVEIRA, E. C.; PIÑARODRIGUES, F. C. M. Análise de sementes. In: AGUIAR, J. B.; PIÑA-RODRIGUES, F. C. M.; FIGLIOLIA, M. B. (Eds.). Sementes florestais tropicais. Brasília, DF: Abrates, 1993. p. 134-174.

FILGUEIRA, F. A. R. Novo manual de olericultura: agrotecnologia moderna na produção e comercialização de hortaliças. Viçosa: UFV, 2000.

FREITAS, R. A.; NASCIMENTO, W. M.; COIMBRA, K. G. Maturação e qualidade de sementes de repolho de verão sob condições tropicais. Horticultura Brasileira, Campinas, v. 25, n. 4, p. 586-589, 2007.

GENTIL, P. E.; TORRES, S. B. Umedecimento do substrato e germinação de sementes de maxixe (Cucumis anguria L.). Revista Brasileira de Sementes, Londrina, v. 23, n. 2, p. 113-116, 2001. 
LEDO, F. J. S.; SOUZA, J. A.; SILVA, M. R. Avaliação de cultivares e híbridos de repolho no Estado do Acre. Horticultura Brasileira, Campinas, v. 18, n. 2, p. 138140, 2000.

MAGUIRE, J. O. Speed of germination: aid in selection and evaluation for seedling emergence and vigor. Crop Science, Madison, v. 2, n. 2, p. 176-177, 1962.

MARCOS FILHO, J. Fisiologia de sementes de plantas cultivadas. Piracicaba: Fealq, 2005.

MENEZES, N. L.; SILVEIRA, T. L. D.; STORCK, L. Efeito do nível de umedecimento do substrato sobre a germinação de cucurbitáceas. Ciência Rural, Santa Maria, v. 23 , n. 2, p. $157-160,1993$.

NASCIMENTO, W. Temperatura x germinação. Seed News, Pelotas, v. 4, n. 4, p. 44-45, 2000.

NOVEMBRE, A. D. L. C; MARCOS FILHO, J. Estudo da metodologia para condução do teste de germinação em sementes de algodão deslintadas mecanicamente. Revista Brasileira de Sementes, Pelotas, v. 21, n. 2, p. 187-193, 1999.

PHANEENDRANATH, B. R. Influence of amount of water in the paper towel on standard germination tests. Journal of Seed Technology, New York, v. 5, n. 2, p. 82$87,1980$.
PESKE, S. T. Germination and emergence of soybean seeds as related to moisture stress. Mississippi: Mississippi State University, 1983.

PACHECO, M. V. et al. Efeito de temperaturas e substratos na germinação de sementes de Myracrodruon urundevuva Fr. All. (ANACARDIACEAE). Revista Árvore, Viçosa, v. 30, n. 3, p. 359-367, 2006.

POPINIGIS, F. Fisiologia da semente. Brasília, DF: Agiplan, 1985.

TANAKA, M. A. S.; MARIANO, M. I. A.; LEÃO, N. V. $\mathrm{M}$. Influência da quantidade de água no substrato sobre a germinação de sementes de amendoim. Revista Brasileira de Sementes, Pelotas, v. 13, n. 1, p. 73-76, 1991.

VARELA, V. P.; RAMOS, M. B. P.; MELO, M. de F. F. Umedecimento do substrato e temperatura na germinação de sementes de angelim-pedra (Dinizia excelsa Ducke). Revista Brasileira de Sementes, Pelotas, v. 27, n. 2, p. 130$145,2005$. 